\title{
THE BENEFICIAL EFFECTS OF DRYLAND TRAINING ON PREPUBERTAL SWIMMERS - A CASE STUDY
}

\author{
Sonia ALBU ${ }^{1 *}$ \\ ${ }^{1}$ National University of Physical Education and Sport, Faculty of Physical Education and Sport, Bucharest, \\ Romania
}

https://doi.org/10.35189/dpeskj.2021.60.3.11

\begin{abstract}
Dryland training is an important part of any competitive swimmer's programme. However, this non-specific training is usually neglected in prepubertal swimmers, its importance being recognised more often in junior and senior swimmers. This paper is a case study regarding the beneficial effects that a well-developed and suitable dryland training programme can have on a prepubertal swimmer's results. The participant in this case study was a Romanian male swimmer born in 2010, who got the highest score at the National Championships in 2020. The detailed dryland programme (developed by the author of the current study) was followed by the athlete for a period of 7 months. The implementation of this programme took place between two national championships (October 2020 - June 2021). The specific objectives were: winning the title of national champion in 50-meter butterfly and making a progress of 2 seconds; ranking among the top three swimmers in 100-meter freestyle and making a progress of 4 seconds. After applying the programme, the athlete made a progress of 2.57 seconds and won first place in 50-meter butterfly. In 100-meter freestyle, he made a progress of 6.34 seconds and won second place. This paper emphasises the beneficial effects of an organised dryland training programme and also proposes a model of such a plan that can be followed by prepubertal swimmers.
\end{abstract}

Keywords: dryland training, prepubertal swimmers, case study.

\section{Introduction}

Dryland training defines all movements and exercises performed out of the water with the purpose of improving in-water performance. In the swimming world, dryland training is also known as strength and conditioning training.

During the last 50 years, muscle strength training (ST) has been a major topic for coaches, athletes and researchers (Marques et al., 2008). Over the years, adding dryland training to a swimmer's programme has been proven beneficial and has allowed many athletes to enhance their swimming performance. Dryland training helps improve strength, flexibility and mobility, all of which are very important for a swimmer. Swimming is one of the few activities that engage all muscle groups. Marques et al. (2011) state that a specific strength training programme can improve the rate of force production and contribute to increased performance. Other authors believe that "strength training using dry-land regimens may enhance the ability to produce propulsive forces in-water, especially in short distance events" (Morouço et al., 2012, p. 557).

Although dryland training is an important part of a swimmer's programme, "investigations in young competitive swimmers are few in comparison to those carried out in adult/elite swimmers" (Marques et al., 2011, p. 10), therefore this paper can contribute to the current level of knowledge and information on the topic addressed.

Dryland training has been reported to have a positive influence on sprint performance in swimming in several research papers such as Effects of Dry-Land Strength and Conditioning 
Programs in Age Group Swimmers (Amaro et al., 2017), Training Adaptations for Optimal Performance (Costill, 1999) and Effects of Maximal Strength Training on Sprint Performance of Competitive Swimmers (Strass, 1988). According to Lopes et al. (2021), after implementing a dryland training programme, the increase in upper-body strength was obvious and improvements in 50-meter and 100-meter swimming performance were found. The above authors believe that strength training could be very useful to improve strength as well as swimming performance and swimming technique in lower-level athletes and/or with less experience in this type of training. The mentioned paper highlights that, despite the theory that dryland strength training is probably not specific enough to improve sprint performance, their experimental group that combined swimming and dryland resistance training tended to demonstrate greater improvement in sprint performance than the control group that only took part in swimming training. Moreover, better performance was also recorded over longer distances by swimmers with a higher level of strength as proven in articles such as The Power Output and Sprinting Performance of Young Swimmers (Barbosa et al., 2015), Relationship between Performance, Dry-Land Power and Kinematics in Master Swimmers (Espada et al., 2016) and Tethered Swimming Can Be Used to Evaluate Force Contribution for ShortDistance Swimming Performance (Morouço et al., 2014).

Lopes et al. (2021) revealed in their study that "ST increased specific strength and could be used to maximize swimmer performance by adapting swimming technical patterns enhancing swimming economy" (p. 38), adding that "ST combined with swimming training allowed the development of dry-land strength and improved swimming performance resulting from some adjustments to the swimming technique" (p. 37). Marques et al. (2020) believe that "coaches and strength and conditioning professionals should consider including inseason dry-land ST programs within the training routine in order to obtain further improvements in swimming performance" (p. 80).

Other beneficial effects of dryland training are the reduced risk of injury and the increased stroke rate and distance per stroke. It is generally accepted that dryland training combined with specific swimming training is more effective than in-water training alone.

Strength training is sometimes considered to have negative effects on children and there is an ongoing debate about the age at which this type of training should begin. There is an assumption that the early start of strength training may stunt growth, affect bone health or increase the risk of injury (Hekmati, 2019). According to the American Academy of Pediatrics (2008), children aged 7 years can start a strength training programme but they "also should have advanced to a certain level of skill proficiency in their sport" (p. 837) before engaging in such a programme for the strength to have some potential value. On the other hand, Stricker et al. (2020) identified some misconceptions regarding strength training in children, for example: a child is unable to increase strength before puberty; resistance training may stunt growth.

Simple dryland strength is "significantly associated with sprint swimming performance in young competitive swimmers" (Garrido et al., 2010, p. 240). Nugent et al. (2018) also think that young swimmers aged 7-13 are an athletic population that can benefit from a strength and conditioning programme. However, not all studies on this topic have shown obvious beneficial effects of dryland training on young swimmers. For instance, Sadowski et al. (2012) indicated "slightly greater improvements in sprint performance" (p. 77) but "the main 
data could not clearly state that power training allowed an enhancement in swimming performance" (p. 77).

Dryland training in swimming is more than strength training. It includes every type of training that a swimmer does out of the water, such as conditioning training or mobility and flexibility training. It is well-known that strength training can limit mobility and flexibility and can have a negative impact on the performance of a swimmer. Therefore, it is crucial for strength training to be combined with flexibility and mobility training, for example, static stretching exercises. It is important for swimmers to perform at least 15 minutes of static stretching exercises if they start doing some kind of dryland training.

This paper is a case study that aims to highlight the importance and beneficial effects of dryland training on the performance of prepubertal swimmers.

\section{Methodology}

The research methods used were the following: literature review, case study, mathematical statistics, graphical representation method.

\section{Participants}

The participant in this case study was a Romanian male swimmer born in February 2010. At the beginning of the study, he was 10 years and 8 months old, and at the end of the study, he was 11 years and 4 months old. This athlete was chosen because he got the highest score at the National Championships in October 2020, and we wanted to emphasise what a difference dryland training can make for a swimmer already having good swimming results and rankings.

\section{Procedure}

A detailed dryland programme was designed for the male athlete participating in this research. Prior to that, he had not followed a systematised and organised dryland plan.

The period in which the case study took place was October 2020 - June 2021, between two national championships. The objectives for June 2021 were: winning the title of national champion in 50-meter butterfly and making a progress of 2 seconds compared to the National Championships in October; ranking among the top three swimmers in 100-meters freestyle and making a progress of 4 seconds. These two swimming events were chosen because both were national championships.

The dryland training that was developed for the research participant covered three main areas and types of training: strength training, mobility and flexibility training, conditioning training. The programme was designed taking into account the somato-functional indices of the swimmer's age and the characteristics of growth and development of this age. For example, one of the specific features of this age is that prepubertal children can experience increases in strength in the absence of muscle hypertrophy. Therefore, this period is optimal to start a dryland programme that also includes strength exercises. 
Strength training included bodyweight exercises and resistance band exercises. No weight exercises were used. Three different strength programmes were implemented so that the participant did not get used to a programme. All athletes should regularly change and adjust their strength training routines for several reasons. First, this will prevent boredom associated with doing the same exercises over and over again. This also prevents reaching a plateau in performance and training results. Once the human body has adapted to a routine, it will be difficult to see any further gains. In other words, if the body gets used to a certain type of exercise, the programme may no longer have the expected results. "Warm-up before physical activity is commonly accepted to be fundamental, and any priming practices are usually thought to optimize performance" (Neiva et al., 2014, p. 319), so all three programmes started with dynamic warm-up for 10-15 minutes. According to Law and Herbert (2007), warm-up can also reduce muscle soreness. Furthermore, all training programmes ended with cool-down. Costa et al. (2011) say that appropriate cool-down strategies can enhance the recovery process.

Mobility and flexibility training included static stretching exercises for all body segments and joints. It is already known that mobility and flexibility are essential in swimming and can greatly influence performance. Therefore, this part of the training was also important because, according to Jansson et al. (2005), competitive swimming in children seems to decrease the range of motion in terms of shoulder rotation. Many authors such as Stamford (1984) and Beaulieu (1981) also recommend stretching to improve performance. Given that our swimmer started a dryland programme including strength training, we wanted to make sure that his mobility and flexibility in the water would not be negatively affected.

Conditioning training consisted of running for 20-30 minutes at a moderate-to-low intensity. Running can have several positive effects such as improving overall endurance and aerobic endurance. It has also been shown that running has a positive influence on a person's mental state and mood. The impact that running can have on human well-being has been demonstrated (Yeh et al., 2017; Shipway \& Holloway, 2010; Skead \& Rogers, 2016; Grunseit et al., 2018).

Specific training refers to in-water training. Our swimmer had 2 hours of specific training per day, 6 times a week. In a training session, he used to swim between 4,000 and 4,500 meters.

Being the first time for the athlete to follow a dryland programme, we mention that, in the first two weeks, he became familiar with all exercises and learned to do them correctly. Thus, the swimmer began to go through the programmes in full only after proving that he was able to correctly perform all types of exercises.

During the months of programme implementation, the three strength programmes underwent minor changes and adaptations, but the basic exercises were as follows:

\section{Dryland training \\ Strength training - Programme no. 1}

Warm-up: 10-15 minutes of dynamic warm-up; dynamic stretching

Ex. 1) 2 series - squats (a series of squats, a series of jump squats)

Ex. 2) 2 series - crunches

Ex. 3) 2 series - leg raises simultaneously - from the initial supine position 
Ex. 4) 2 series - calf raises

Ex. 5) 2 series - mountain climbers

Ex. 6) 2 series - back extensions simultaneously with flutter kicks (prone flutter kicks)

Ex. 7) 2 series - knee push-ups

Ex. 8) 2 series - quadruped opposite elbow to knee

Ex. 9) 2 series - jumping rope (or straight jumps)

Ex. 10) 2 series - high knees/ running on the spot

* 30 seconds work, 30 seconds break (Example: 30" squats, 30" break, 30" jump squats, 30" break, 30" crunches, etc.)

Cool-down: 10-15 minutes of static stretching exercises

Programme duration: 40-50 minutes

\section{Dryland training}

\section{Strength training - Programme no. 2}

Warm-up: 10-15 minutes of dynamic warm-up; dynamic stretching

Programme no. 2 was divided into three parts: legs; arms; abdomen and back

Leg exercises:

Ex. 1) 30" squats, 30" break

Ex. 2) 30" calf raises, 30" break

Ex. 3) 30" straight jumps, 30" break

Ex. 4) 30" jump squats, 30" break

Ex. 5) 30" high knees/running on the spot, 30" break

Arm exercises - with resistance bands:

- series of 10 repetitions on each arm for the main muscle groups: biceps, triceps, deltoid

Abdominal and back exercises

Ex. 1) 30" back extensions, 30" break

Ex. 2) 30" flutter kicks, 30" break

Ex. 3) 30" crunches, 30" break

Ex. 4) 30" flutter kicks, 30" break

Ex. 5) 30" quadruped opposite elbow to knee, 30" break

Cool-down: 10-15 minutes of static stretching exercises

Programme duration: 40-50 minutes

\section{Dryland training \\ Strength training - Programme no. 3}

Warm-up: 10-15 minutes of dynamic warm-up; dynamic stretching Programme no. 3 was divided into two parts: arms, abdomen and back; legs Arm, abdominal and back exercises

Ex. 1) 10 knee push-ups, 30" break

Ex. 2) 30" back extensions, 30" break

Ex. 3) 30" flutter kicks, 30" break

Ex. 4) 30" crunches, 30" break

Ex. 5) 30" flutter kicks, 30" break 


\section{Leg exercises}

Ex. 1) 45" squats, 15 " break

Ex. 2) 45 " calf raises, 15 " break

Ex. 3) 30" straight jumps, 30" break

Ex. 4) 30" jump squats, 30" break

Ex. 5) 30" high knees/running on the spot, 30" break

The programme is performed two times with a 2-minute break between repetitions.

Cool-down: 10-15 minutes of static stretching exercises

Programme duration: 40-50 minutes

Given that the athlete was new to strength training, we used simple bodyweight and resistance band exercises. Therefore, these programmes can be a useful model for a prepubertal swimmer who wants to start working on strength development.

Table 1 shows an example of organising training sessions during a microcycle (a week), but it is worth mentioning that the swimmer did not have the same programme every week. The training sessions were organised according to the athlete's school schedule. For instance, in the first weeks of this study, the swimmer got used to the exercises and did not perform strength training 3 times a week but only 2 times a week. Also, in the weeks leading up to the National Championships, the training volume was decreased. We believe that this example of microcycle can be used to organise the training sessions of prepubertal swimmers, but with certain adaptations depending on the given situation, the proposed objectives and the athlete's characteristics. For instance, a specialist can choose to apply the strength training programme after the specific in-water training. In the present research, this organisation was the best option, taking into account the swimmer's schedule.

Table 1. Example of organising training sessions during a week (microcycle)

\begin{tabular}{|c|c|c|c|c|c|c|}
\hline Monday & Tuesday & Wednesday & Thursday & Friday & Saturday & Sunday \\
\hline $\begin{array}{l}\text { Strength } \\
\text { training }\end{array}$ & & $\begin{array}{l}\text { Strength } \\
\text { training }\end{array}$ & & $\begin{array}{l}\text { Strength } \\
\text { training }\end{array}$ & & $\begin{array}{c}\text { Conditioning } \\
\text { training }\end{array}$ \\
\hline Pr. no. 1 & & Pr. no. 2 & & Pr. no. 3 & & (20-30 minutes \\
\hline $15-15.45$ & & $15-15.45$ & & $15-15.45$ & & $\begin{array}{c}\text { of running at a } \\
\text { moderate-to- } \\
\text { low intensity) } \\
09-09.30\end{array}$ \\
\hline $\begin{array}{c}\text { Specific } \\
\text { training } \\
16-18\end{array}$ & $\begin{array}{c}\text { Specific } \\
\text { training } \\
16-18\end{array}$ & $\begin{array}{c}\text { Specific } \\
\text { training } \\
16-18\end{array}$ & $\begin{array}{c}\text { Specific } \\
\text { training } \\
16-18\end{array}$ & $\begin{array}{c}\text { Specific } \\
\text { training } \\
16-18\end{array}$ & & $\begin{array}{c}\text { Specific } \\
\text { training } \\
10-12\end{array}$ \\
\hline $\begin{array}{l}\text { Mobility and } \\
\text { flexibility } \\
\text { training }\end{array}$ & $\begin{array}{l}\text { Mobility and } \\
\text { flexibility } \\
\text { training }\end{array}$ & $\begin{array}{l}\text { Mobility and } \\
\text { flexibility } \\
\text { training }\end{array}$ & $\begin{array}{l}\text { Mobility and } \\
\text { flexibility } \\
\text { training }\end{array}$ & $\begin{array}{l}\text { Mobility and } \\
\text { flexibility } \\
\text { training }\end{array}$ & Rest day & $\begin{array}{l}\text { Mobility and } \\
\text { flexibility } \\
\text { training }\end{array}$ \\
\hline Static & Static & Static & Static & Static & & Static \\
\hline $\begin{array}{l}\text { stretching } \\
\text { exercises }\end{array}$ & stretching & stretching & stretching & stretching & & stretching \\
\hline $\begin{array}{c}\text { exercises } \\
18-18.20\end{array}$ & exercises & exercises & exercises & exercises & & exercises \\
\hline $18-18.20$ & $18-18.30$ & $18-18.20$ & $18-18.30$ & $18-18.20$ & & $12-12.30$ \\
\hline
\end{tabular}




\section{Results}

After completing the dryland training programme, the participant recorded a progress of 2.57 seconds and won first place in 50-meter butterfly at the National Championships in June 2021 (Figure 1). In 100-meter freestyle, he made a progress of 6.34 seconds and won second place (Figure 2). This translates into a $7.75 \%$ decrease in time for 50 -meter butterfly and a $9.32 \%$ decrease in time for 100-meter freestyle. Therefore, the recorded results exceeded the objectives proposed at the beginning of this study. It is true that these results are also due to the specific in-water training and the biological development of the athlete, so it is difficult to say exactly to what extent dryland training has contributed to his performance. However, taking into account all studies and research on this topic, we strongly believe that the progress made by the athlete is partly due to the dryland training we added to his routine. Moreover, the swimmer stated that he felt the beneficial effects of this programme. One of the problems identified by him at the National Championships in October 2020 was that, in 100-m freestyle, he felt very tired in the second half of the race and could not finish the event as he would have liked. This did not happen at the National Championships in June 2021, which leads us to believe that the programme we added has also contributed to developing the swimmer's specific in-water resistance. Another problem felt by the athlete before the start of the dryland programme was related to joint mobility. The mobility and flexibility training that he followed helped him to improve this area too.

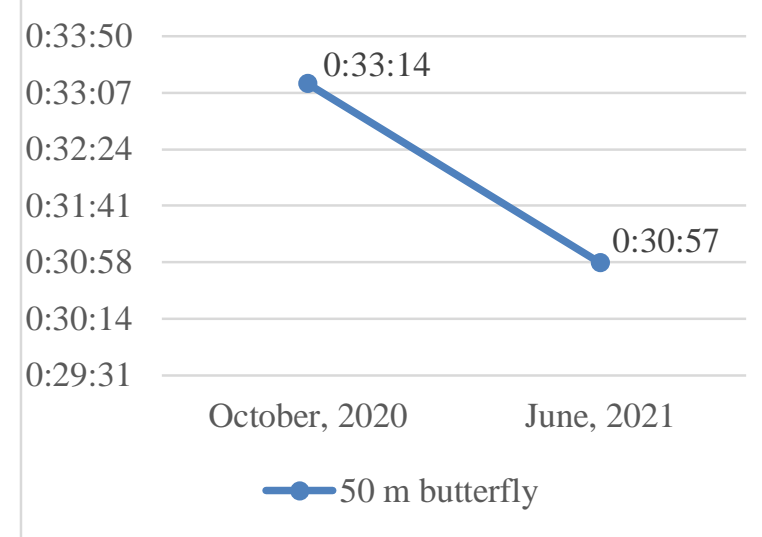

Figure 1. Progress recorded in the 50-m butterfly event

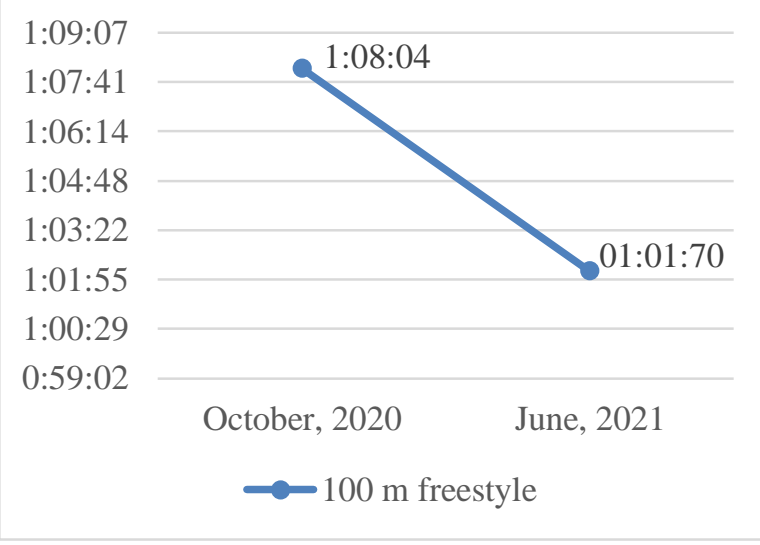

Figure 2. Progress recorded in the 100-m freestyle event

\section{Conclusion}

Dryland training is an important part of any competitive swimmer's programme and is more than strength training. Dryland training for this case study included strength training, mobility and flexibility training as well as conditioning training. The three strength training programmes used for this case study included bodyweight exercises and resistance band exercises. Mobility and flexibility training included static stretching exercises, and conditioning training involved 20-30 minutes of running/jogging at a moderate-to-low intensity. After completing a well-designed and appropriate dryland training programme, the 
investigated prepubertal swimmer improved his performance in both swimming events. In the 50 -m butterfly event, he made a progress of 2.57 seconds from one national championship (October 2020) to another (June 2021). In the 100-m freestyle event, he made a progress of 6.34 seconds. Being a case study with one participant, it is difficult to generalise these results.

Another limitation of this paper is represented by the fact that it is impossible to demonstrate to what extent dryland training has contributed to performance improvement compared to specific in-water training. However, considering the existing scientific research on this topic, we can say that the progress of our athlete was also due to the dryland programme added to his routine.

The present paper brings additional information on the topic of dryland training for prepubertal swimmers. Although there are many articles about dryland training for swimmers, they generally focus on junior and senior swimmers and less on children and prepubertal athletes. The study highlights the importance of starting strength training with basic bodyweight exercises for prepubertal swimmers. Adding a dryland programme to their routine helps improve swimmers' performance at this stage of growth and development. It will also be the basis on which weight training can be built later. Finally, this paper proposes three different strength training programmes and an example of organising training sessions during a microcycle.

\section{References}

Amaro, N. M., Marinho, D. A., Marques, M. C., Batalha, N. P., \& Pe Morouço, P. G. (2017). Effects of dry-land strength and conditioning programs in age group swimmers. Journal of Strength and Conditioning Research, 31(9), 2447-2454. https://doi.org/10.1519/jsc.0000000000001709

American Academy of Pediatrics. (2008). Strength training by children and adolescents. Pediatrics, 121(4), 835-840. https://doi.org/10.1542/peds.2007-3790

Barbosa, T. M., Morais, J. E., Marques, M. C., Costa, M. J., \& Marinho, D. A. (2015). The power output and sprinting performance of young swimmers. Journal of Strength and Conditioning Research, 29(2), 440-450. https://doi.org/10.1519/jsc.0000000000000626

Beaulieu, J. E. (1981). Developing a stretching program. The Physician and Sportsmedicine, 9(11), 59-69. https://doi.org/10.1080/00913847.1981.11711207

Costa, P., de Oliveira Medeiros, H. B., \& Fukuda, D. (2011). Warm-up, stretching, and cooldown strategies for combat sports. Strength and Conditioning Journal, 33(6), 71-79. https://doi.org/10.1519/SSC.0b013e31823504c9

Costill, D. L. (1999). Training adaptations for optimal performance. In K. L. Keskinen, P. V. Komi, \& A. P. Hollander (Eds.), Biomechanics and medicine in swimming VIII (pp. 381390). Gummerus Printing House.

Espada, M. C., Costa, M. J., Costa, A. M., \& Silva, A. J. (2016). Relationship between performance, dry-land power and kinematics in master swimmers. Acta of Bioengineering and Biomechanics, 18(2), 145-151. DOI: 10.5277/ABB-00223-2014-02

Garrido, N., Marinho, D. A., Barbosa, T. M., Costa, A. M., Silva, A. J., Perez, T., Jose, A., \& Marques, M. C. (2010). Relationships between dry land strength, power variables and short sprint performance in young competitive swimmers. Journal of Human Sport and Exercise, 5(2), 240-249. https://doi.org/10.4100/JHSE.2010.52.12

Grunseit, A., Richards, J., \& Merom, D. (2018). Running on a high: Parkrun and personal well-being. BMC Public Health, 18: 59. https://doi.org/10.1186/s12889-017-4620-1 
Hekmati, D. (2019). Swimmer strength tech tip: Age to start dryland training or strength training. https://www.swimmingworldmagazine.com/news/swimmer-strength-tech-tipage-to-start-training/

Jansson, A., Saartok, T., Werner, S., \& Renström, P. (2005). Evaluation of general joint laxity, shoulder laxity and mobility in competitive swimmers during growth and in normal controls. Scandinavian Journal of Medicine \& Science in Sports, 15(3), 169-176. https://doi.org/10.1111/j.1600-0838.2004.00417.x

Law, R. Y. W., \& Herbert, R. D. (2007). Warm-up reduces delayed-onset muscle soreness but cool-down does not: A randomised controlled trial. Australian Journal of Physiotherapy, 53(2), 91-95. https://doi.org/10.1016/S0004-9514(07)70041-7

Lopes, T., Neiva, H., Gonçalves, C. A., Nunes C., \& Marinho, D. A. (2021). The effects of dry-land strength training on competitive sprinter swimmers. Journal of Exercise Science \& Fitness, 19(1), 32-39. https://doi.org/10.1016/j.jesf.2020.06.005

Marques, M. C., van den Tillaar R., Vescovi J. D., \& González-Badillo J. J. (2008). Changes in strength and power performance in elite senior female professional volleyball players during the in-season: A case study. Journal of Strength and Conditioning Research, 22(4), 1147-1155. https://doi.org/10.1519/jsc.0b013e31816a42d0

Marques, M. C., Zajac, A., Pereira, A., \& Costa, A. M. (2011). Strength training and detraining in different populations: Case studies. Journal of Human Kinetics, 29A(Special Issue), 7-14. https://doi.org/10.2478/v10078-011-0052-7

Marques, M. C., Yáñez, G., Badillo, J., Marinho, D., \& Rodriguez-Rosell, D. (2020). Inseason strength training in elite junior swimmers: The role of the low-volume, highvelocity training on swimming performance. Journal of Human Kinetics, 74(1), 71-84. https://doi.org/10.2478/hukin-2020-0015

Morouço, P. G., Marinho, D. A., Amaro, N. M., \& Perez-Turpin, J. A. (2012). Effects of dryland strength training on swimming performance: A brief review. Journal of Human Sport and Exercise, 7(2), 553-559. https://doi.org/10.4100/jhse.2012.72.18

Morouço, P. G., Marinho, D. A., Keskinen, K. L., \& Gonzalez-Badillo, J. J. (2014). Tethered swimming can be used to evaluate force contribution for short-distance swimming performance. Journal of Strength and Conditioning Research, 28(11), 3093-3099. https://doi.org/10.1519/jsc.0000000000000509

Neiva, H. P., Marques, M. C., Barbosa, T. M., \& Izquierdo, M. (2014). Warm-up and performance in competitive swimming. Sports Medicine, 44(3), 319-330. https://doi.org/10.1007/s40279-013-0117-y

Nugent, F. J., Comyns, T. M., \& Warrington, G. D. (2018). Strength and conditioning considerations for youth swimmers. Strength and Conditioning Journal, 40(2), 31-39. https://doi.org/10.1519/SSC.0000000000000368

Sadowski, J., Mastalerz, A., Gromisz, W., \& Niznikowski, T. (2012). Effectiveness of the power dry-land training programmes in youth swimmers. Journal of Human Kinetics, 32(1), 77-86. https://doi.org/10.2478/v10078-012-0025-5

Shipway, R., \& Holloway, I. (2010). Running free: Embracing a healthy lifestyle through distance running. Perspectives in Public Health, 130(6), 270-276. https://doi.org/10.1177/1757913910379191

Skead, N. K., \& Rogers, S. L. (2016). Running to well-being: A comparative study on the impact of exercise on the physical and mental health of law and psychology students. International Journal of Law and Psychiatry, 49(A), 66-74. https://doi.org/10.1016/j.ijlp.2016.05.012

Stamford, B. (1984). Flexibility and stretching. The Physician and Sportsmedicine, 12(2): 171. https://doi.org/10.1080/00913847.1984.11701783 
Strass, D. (1988). Effects of maximal strength training on sprint performance of competitive swimmers. Swimming Science V, International Series of Sport Sciences, 18, 149-156.

Stricker, P. R., Faigenbaum, A. D., \& McCambridge, T. M. (2020). Resistance training for children and adolescents. Pediatrics, 145(6): e20201011. https://doi.org/10.1542/peds.2020-1011

Yeh, H., Stone, J. A., Churchill, S. M., Brymer, E., \& Davids, K. (2017). Physical and emotional benefits of different exercise environments designed for treadmill running. International Journal of Environmental Research and Public Health, 14(7): 752. https://doi.org/10.3390/ijerph14070752 